ARTICLE

https://doi.org/10.1038/s41467-020-19293-9

\title{
Copper(I)-catalyzed asymmetric 1,6-conjugate allylation
}

\author{
Chang-Yun Shi ${ }^{1,2}$, Zhi-Zhou Pan ${ }^{2}$, Ping Tian (10) ${ }^{1 凶} \&$ Liang Yin (10) ${ }^{1,2}{ }^{凶}$
}

Catalytic asymmetric conjugate allylation of unsaturated carbonyl compounds is usually difficult to achieve, as 1,2-addition proceeds dominantly and high asymmetric induction is a challenging task. Herein, we disclose a copper(I)-NHC complex catalyzed asymmetric 1,6conjugate allylation of 2,2-dimethyl-6-alkenyl-4H-1,3-dioxin-4-ones. The phenolic hydroxyl group in NHC ligands is found to be pivotal to obtain the desired products. Both aryl group and alkyl group at $\delta$-position are well tolerated with the corresponding products generated in moderate to high yields and high enantioselectivity. Moreover, both 2-substituted and 3-substituted allylboronates serve as acceptable allylation reagents. At last, the synthetic utility of the products is demonstrated in several transformations by means of the versatile terminal olefin and dioxinone groups.

\footnotetext{
${ }^{1}$ The Research Center of Chiral Drugs, Innovation Research Institute of Traditional Chinese Medicine and China-Thailand Joint Research Institute of Natural Medicine, Shanghai University of Traditional Chinese Medicine, 1200 Cailun Road, 201203 Shanghai, China. ${ }^{2}$ CAS Key Laboratory of Synthetic Chemistry of Natural Substances, Center for Excellence in Molecular Synthesis, Shanghai Institute of Organic Chemistry, University of Chinese Academy of Sciences,

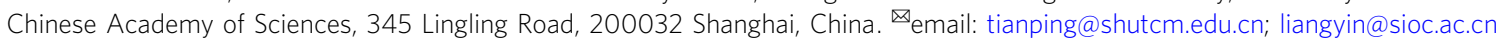


C atalytic asymmetric conjugate addition of various metal reagents to unsaturated compounds is identified as one of the most important tools in the construction of carboncarbon bonds in organic synthesis ${ }^{1-3}$. Among the various carbonbased metal reagents, allyl metal reagents exhibit advantages over other alkyl metal reagents as the olefin moiety is more synthetically versatile. Non-enantioselective methods based on different allyl metal (such as, Si, B, Zn, and Sn) species have been disclosed in the past several decades ${ }^{4}$. However, the catalytic asymmetric conjugate addition with allyl metal reagents is still in its infancy as such a reaction is not easy to achieve due to the competitive 1,2-addition and the difficulty in the asymmetric induction.

Indeed, catalytic asymmetric allylation of aldehyde, ketone, and imine receives significant research efforts from the chemical community, which leads to the identification of efficient catalytic systems based on $\mathrm{Cu}^{5-16}, \mathrm{Zn}^{17,18}, \mathrm{Ag}^{19-22}$, and $\mathrm{In}^{23,24}$. The proposed six-membered ring transition state formed by the coordination of the allyl metal species to carbonyl group allows excellent asymmetric induction. Especially, copper(I)-catalysts serve as powerful weapons to enable the highly enantioselective allylation of carbonyl groups and imines ${ }^{5-16}$. However, the affinity of the highly nucleophilic allylcopper(I) species to carbonyl group set up an obstacle on the conjugate allylation. For example, in the presence of $10 \mathrm{~mol} \%$ copper(I)-(R)-BINAP, 2 equiv allylboronate, and 1 equiv $\mathrm{LiO}^{t} \mathrm{Bu}$, the allylation of $\alpha, \beta$ unsaturated ester produced tertiary alcohol only and the 1,4conjugate allylation product was not obtained (Fig. 1a). Moreover, without the assistance of the six-membered ring transition state, there is a concern about the enantioselectivity in the conjugate allylation.

Several research group made their contributions in the challenging catalytic asymmetric conjugate allylation (Fig. 1b $)^{25-33}$. Snapper reported a $\mathrm{Cu}(\mathrm{II})-\mathrm{BOX}$-catalyzed asymmetric conjugate allylation of unsaturated cyclic $\beta$-ketoesters with allylsilane ${ }^{25}$. In 2007, Morken and co-workers

a

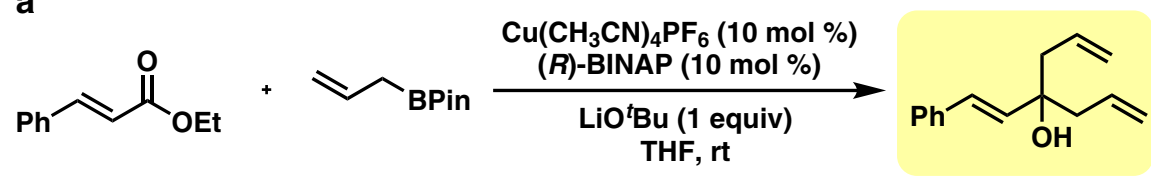

b

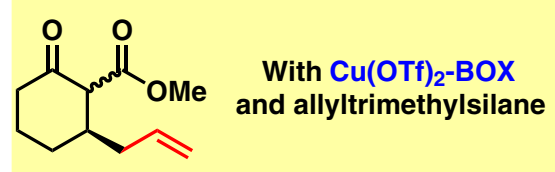

Snapper's reaction (2008)

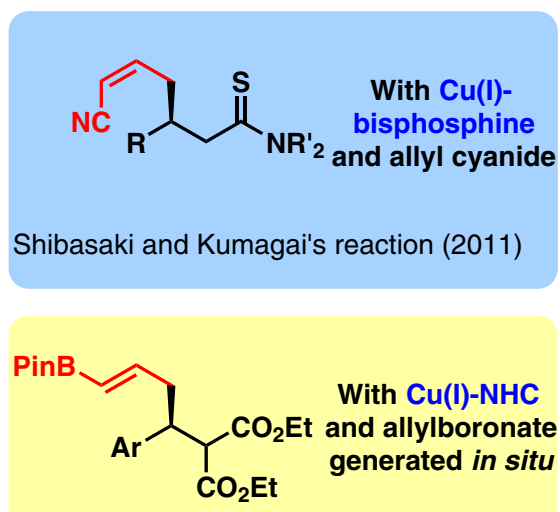

Hoveyda's reaction (2016 and 2019)

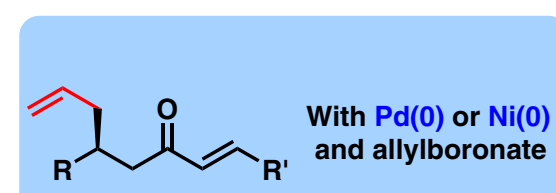

Morken's reaction (2008 and 2011)

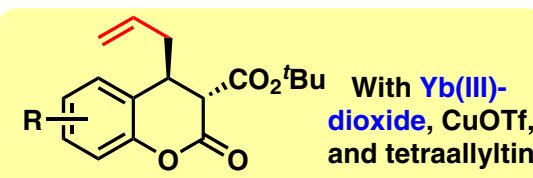

Feng's reaction (2011)

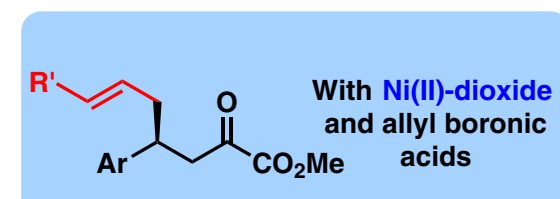

Feng and Dong's reaction (2019)

C
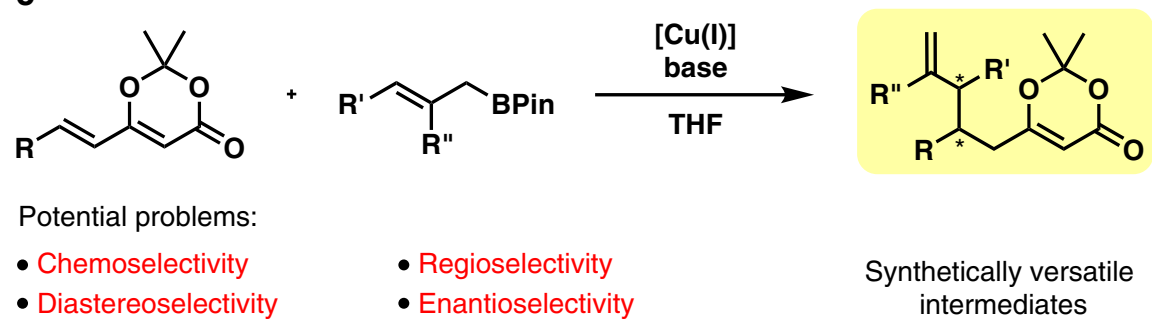

Fig. 1 Prior arts in catalytic asymmetric conjugate allylation and our work. a Failed copper(I)-catalyzed asymmetric conjugate allylation. b Reported catalytic asymmetric conjugate allylation. c This work: copper(I)-catalyzed asymmetric conjugate 1,6-allylation. 
disclosed an impressive Ni-catalyzed regioselective conjugate allylation of $\alpha, \beta-\alpha^{\prime}, \beta^{\prime}$-di-unsaturated ketones ${ }^{26}$. Later, the Morken group uncovered two efficient methods to carry out the catalytic asymmetric version in excellent control of the regioselectivity with either a palladium catalyst or a nickel catalys $\mathrm{t}^{27,28}$. The Hoveyda group achieved a three-component reaction of 1,3-butadiene, $\mathrm{B}_{2} \mathrm{Pin}_{2}$ and alkylidenemalonates in high yields with excellent enantioselectivity ${ }^{29}$. However, aliphatic substituents were not well tolerated at the $\beta$-position. The same group also succeeded in the catalytic enantioselective 1,6-conjugate allylation of $\alpha, \beta, \gamma, \delta$-unsaturated diesters with $\mathrm{B}_{2} \mathrm{Pin}_{2}$ and allenes ${ }^{30,31}$. In 2011, the Feng group achieved an asymmetric conjugate allylation of activated unsaturated lactones with a bimetallic catalytic system ${ }^{32}$. In 2019 , the same group reported a formal catalytic asymmetric 1,4-allylation of $\beta, \gamma$-unsaturated $\alpha$-ketoesters ${ }^{4}$. In fact, the formal conjugate allylation was enabled by the allylation of the ketone group and the following oxy-Cope rearrangement. Unfortunately, alkyl was not well tolerated at the $\gamma$-position as only moderate enantioselectivity was observed. Moreover, Shibasaki and Kumagai uncovered a catalytic asymmetric conjugate allylation of $\alpha, \beta$-unsaturated thioamides with allyl cyanide under protontransfer conditions ${ }^{33}$. In view of the above achievements, we are interested in developing a catalytic asymmetric conjugate 1,6allylation with more general substrate structure and broader substrate scope.

Copper(I)-catalyzed asymmetric 1,6-addition with alkyl metal reagents (such as organozinc reagent and Grignard reagent) has been reported as a powerful tool to regioselectively construct carbon-carbon bonds ${ }^{34-46}$. Herein, we disclose an asymmetric 1,6-conjugate allylation of 2,2-dimethyl-6-alkenyl-4H-1,3-dioxin-4-one with a copper(I)-NHC catalyst (Fig. 1c). The 2,2-dimethyl-4H-1,3-dioxin-4-one moiety is an equivalent of the synthetically versatile $\beta$-keto-ester group and the product containing both an allyl group and a dioxinone group allows further structure elaboration. Furthermore, in view of the bulky steric hindrance around the carbonyl group and the relative stability of the lactone moiety, it is envisioned that the highly nucleophilic allylcopper(I) species would not touch the carbonyl group in the dioxinone and thus would attack the less hindered conjugate carbon-carbon double bond to give the desired 1,6-allylation.

\section{Results}

Conditions optimization. First of all, the catalytic asymmetric conjugate allylation of (E)-2,2-dimethyl-6-(4-phenylbut-1-en-1yl)-4H-1,3-dioxin-4-one (1a) with bench-stable allylboronate 2 was studied in the presence of $5 \mathrm{~mol} \% \mathrm{Cu}\left(\mathrm{CH}_{3} \mathrm{CN}\right)_{4} \mathrm{PF}_{6}, 6 \mathrm{~mol} \%$ $(R)$-BINAP, and 1 equiv $\mathrm{LiO}^{t} \mathrm{Bu}$ (Table 1 , entry 1 ). The conjugate allylation proceeded smoothly to afford product $3 \mathbf{a}$ in $25 \%$ yield with $9 \%$ ee. Then, screening of commercially available bisphosphine ligands was performed and proved to be fruitless (entries 2-6). Especially, $(R, R)-\mathrm{Ph}-\mathrm{BPE}$, the previously reported best ligand for the copper(I)-catalyzed allylation of ketones ${ }^{9,11,13}$, only led to $38 \%$ ee (entry 3 ). Moreover, ferrocene-embedded bisphosphine ligands, such as $\left(R, R_{P}\right)$-TANIAPHOS and $(R)-(S)$ JOSIPHOS, were not effective either (entries 5-6). Obviously, copper(I)-bisphosphine catalyst did not suit this conjugate 1,6allylation.

Then, we turned our attention to NHC ligands (Table 1). Five NHC ligands were synthesized according to literature methods ${ }^{47-49}$. NHC-L1 was completely ineffective to get asymmetric induction in this 1,6-conjugate allylation (entry 7). A small but promising $8 \%$ ee was obtained in the reaction with NHC-L2 (entry 8). Since phenol-containing NHCs (including NHC-L3-L5) were identified as powerful ligands in some copper(I)-catalyzed enantioselective reactions by the Sawamura Group ${ }^{49-52}$, NHC-L3 was tried in our reaction, which provided $3 a$ in $10 \%$ yield with $64 \%$ ee (entry 9 ). To our joy, $90 \%$ ee was observed with NHC-L4 (entry 10). However, decreased enantioselectivity $(82 \%$ ee) was obtained in the reaction with bulkier NHC-L5 (entry 11). The yield was increased to $50 \%$ by using $10 \mathrm{~mol} \%$ copper(I) salt and $12 \mathrm{~mol} \%$ NHC-L4 (entry 12). By increasing the amount of $\mathrm{LiO}^{t} \mathrm{Bu}$ from 1 equiv to 2 equiv, the yield was further increased to $85 \%$ with $89 \%$ ee (entry 13 ). Performing the reaction at $-20^{\circ} \mathrm{C}$ resulted in increased enantioselectivity ( $95 \%$ ee) but with decreased yield (53\%) (entry 14). The yield was enhanced to $84 \%$ yield with $94 \%$ ee at $-20^{\circ} \mathrm{C}$ by using 3 equiv allylboronate and 3 equiv $\mathrm{LiO}^{t} \mathrm{Bu}$ (entry 15 ).

Substrate scope. With the optimized reaction conditions in hand, the substrate scope of (E)-2,2-dimethyl-6-alkyl-4H-1,3-dioxin-4ones was studied (Fig. 2). Linear alkyls, including ethyl (3b), ${ }^{n}$ propyl (3c), and ${ }^{n}$ heptyl (3d), were well tolerated and the corresponding products were isolated in good yields with high enantioselectivity. $\beta$-Branched alkyl ('butyl) (3e) was also accepted at the $\delta$-position. The substrates bearing a $\alpha$-branched alkyl with bigger steric hindrance ( $\mathbf{3 f}$ and $\mathbf{3 g}$ ), afforded the allylated products in moderate yields and slightly decreased enantioselectivity. Then, substrates with an alkyl containing a functional group, such as benzyl (3a), terminal alkene (3h), internal alkyne (3i), alkyl chloride (3j), ester (3k), TBS-ether (3l), and N-Boc (3n) were examined. To our joy, the products were obtained in moderate to high yields and high enantioselectivity. Notably, alkyl chloride and ester group were not touched by the nucleophilic allylcopper-NHC species, demonstrating that allylcopper-NHC species was less nucleophilic than allylcopper-bisphosphine species. Unfortunately, the substrate containing a free alcohol (3m) was not tolerated. A substrate with a preexisting chiral center (3o) was also studied. The allylated product was generated in $72 \%$ yield with $91 \%$ de, indicating that the asymmetric induction was mainly controlled by the copper(I) catalyst. It should be noted that in some cases, the reaction temperature was increased to get good yields.

The reaction conditions were applied to the catalytic asymmetric allylation of (E)-2,2-dimethyl-6-aryl-4H-1,3-dioxin-4-ones with 4 equiv allylboronate (2) as 3 equiv $\mathbf{2}$ generally resulted in inferior yields (Fig. 3). The reaction was not very sensitive to the position of a substituent on the phenyl ring. As the allylated products containing a para-substituent, ortho-substituent, or meta-substituent were isolated in moderate to high yields with uniformly high enantioselectivity $(\mathbf{5 a}-\mathbf{5 o})$. It was noted that substrates with electron-withdrawing groups led to lower yields but with maintained enantioselectivity (5d-5f, $\mathbf{5} \mathbf{~ m}$, and $\mathbf{5 o}$ ). Moreover, substrates with electron-donating groups served as competent substrates as the corresponding products were furnished in good yields with high enantioselectivity $(\mathbf{5 b}-\mathbf{5 c}$, $5 \mathbf{h}-5 \mathbf{i}$, and $5 \mathbf{k}-5 \mathbf{l}$ ).

The phenyl group at $\delta$-position was successfully changed to 2-naphthyl group without affecting both yield and enantioselectivity significantly (5p). Moreover, several heteroaryl groups, including 3-pyridyl (5q), 2-furanyl (5r), 2benzofuranyl (5s), 3-benzothienyl (5t), and 3-N-Boc-indolyl $(5 \mathbf{u})$, were successfully tolerated at the $\delta$-position. The corresponding products were furnished in moderate yields with uniformly high enantioselectivity. It should be pointed out that the reaction temperature varied in order to get good yields. The absolute configuration of $\mathbf{5 a}$ was determined to be $S$ by its transformation to a known compound (for the details, see SI). 
ARTICLE

NATURE COMMUNICATIONS | https://doi.org/10.1038/s41467-020-19293-9

Table 1 Optimization of reaction conditions ${ }^{a}$.

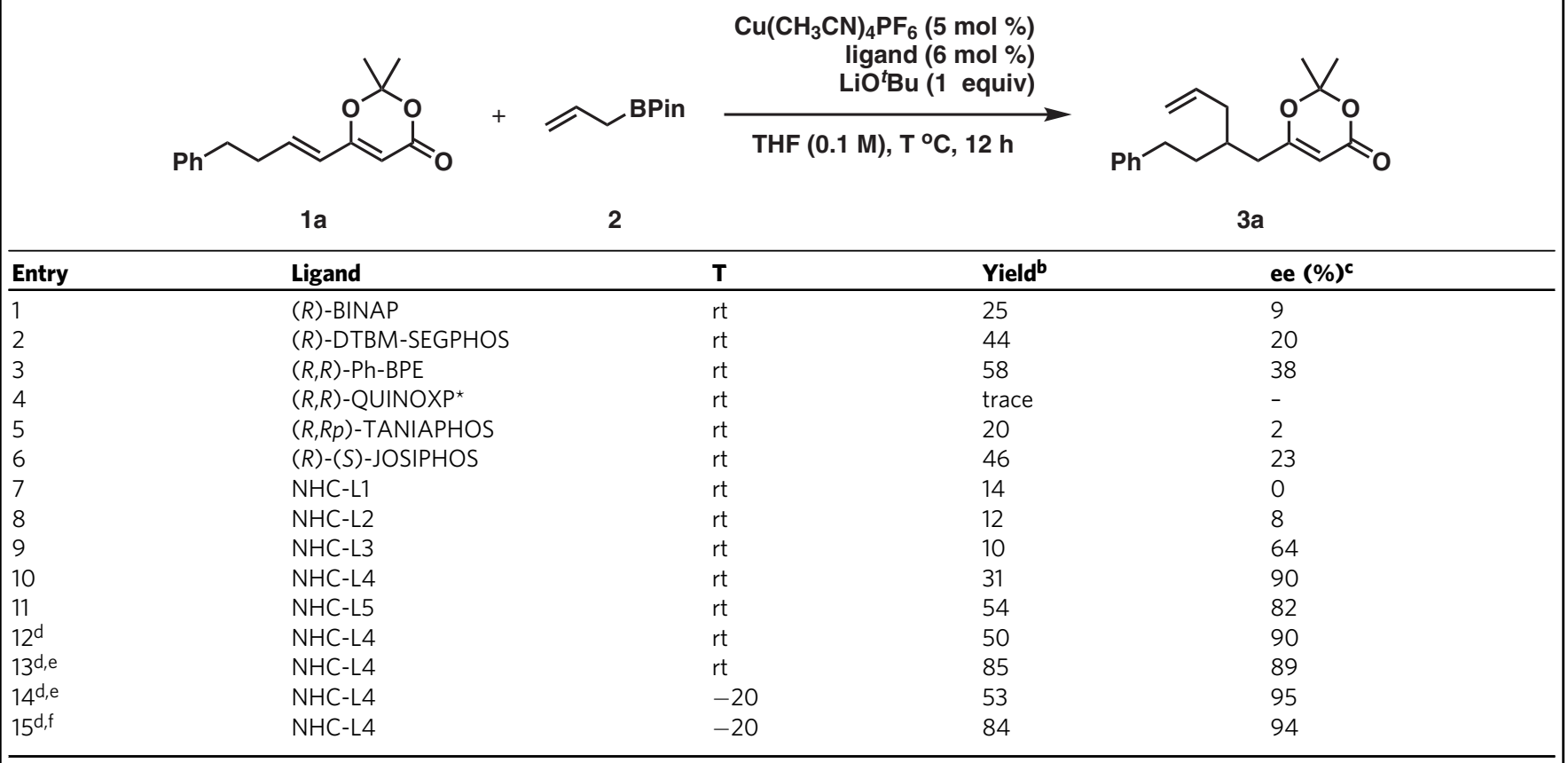

a: $0.1 \mathrm{mmol}$, 2: $0.2 \mathrm{mmol}$.

betermined by ${ }^{1} \mathrm{H}$ NMR analysis of reaction crude mixture using mesitylene as an internal standard.

'Determined by chiral-stationary-phase HPLC analysis.

$\mathrm{d}_{10 \mathrm{~mol}} \% \mathrm{Cu}\left(\mathrm{CH}_{3} \mathrm{CN}\right)_{4} \mathrm{PF}_{6}$ and $12 \mathrm{~mol} \% \mathrm{NHC}$-L4 were used.

${ }^{2} 2$ equiv $\mathrm{LiO}^{t} \mathrm{Bu}$ were employed.

f 3 equiv $\mathbf{2}$ and 3 equiv $\mathrm{LiO}^{t} \mathrm{Bu}$ were employed.<smiles>c1ccc(-c2ccc3ccccc3c2-c2ccc3ccccc3c3cccc2-3)cc1</smiles><smiles>CCCCC(=O)c1ccc2c(c1-c1c(P)ccc3c1OCO3)OCO2</smiles>

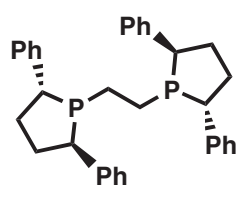

$(R, R)-\mathrm{Ph}-\mathrm{BPE}$

$\mathrm{Ar}=3,5-\mathrm{Bu}_{2}-4-\mathrm{OMe}-\mathrm{Ph}$

(R)-DTBM-SEGPHOS

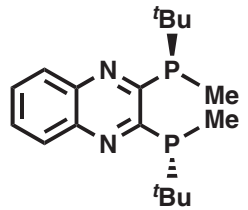

$(R, R)$-QUINOXP*

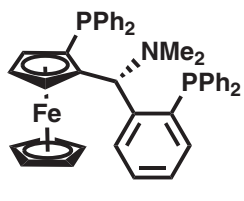

$\left(R, R_{p}\right)$-TANIAPHOS

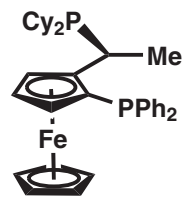

(R)-(S)-JOSIPHOS<smiles>Cc1cc(C)c(N2C=[N+]3C(=N[C@H](c4ccccc4)[C@H]3c3ccccc3)c3ccccc32)c(C)c1</smiles><smiles>Cc1cc(C)c(N2C=[N+]([C@H](CO)C(C)C)CC2)c([P+](F)(F)F)c1</smiles><smiles>Cc1cc(C)c(N2C=[N+](c3c(O)ccc4ccccc34)[C@H](c3ccccc3)[C@H]2c2ccccc2)c(C)c1</smiles><smiles>Cc1cc(C(F)(F)F)cc([AlH2])c1N1C=[N+](c2c(O)ccc3ccccc23)[C@H](c2ccccc2)[C@H]1c1ccccc1</smiles>

NHC-L1·HBF 4

NHC-L2·HPF 6

NHC-L3·HBF 4

$\mathrm{NHC}-\mathrm{L} 4 \cdot \mathrm{HCl}$

NHC-L5•HBF

The absolute configurations of other products (3 and 5) were deduced by analogy.

Then, the 1,6 -conjugate allylation with 2-substituted allylboronates (6-8) was investigated as shown in Fig. 4. Several aryl groups, including phenyl, 2-F-phenyl, and 3-methylphenyl, were well tolerated at the $\delta$-position in the reaction with 6 . The corresponding products $(\mathbf{9 a}-9 \mathbf{c})$ were obtained in $57 \%-63 \%$ yield with $93 \%-97 \%$ ex. An alkyl group, such as 2-phenyl-ethyl, was also acceptable at the $\delta$-position (ad). 2-Methyl group in allylboronate $\mathbf{6}$ was successfully extended to 2-benzyl and ${ }^{n}$ hexyl without eroding both yields and enantioselectivity (10-11). Moreover, the reactions of both
3-methyl-(E)-allylboronate (12a) and 3-methyl-(Z)-allylboronate $(\mathbf{1 2 b})$ were studied as shown in Fig. 5. The diastereoseelective allylation of $\mathbf{4 j}$ and $\mathbf{1 2 a}$ proceeded smoothly to afford $\mathbf{1 3}$ in moderate yield with moderate diastereoselectivity and excellent enantioselectivity. Surprisingly, the reaction with 12b also furnished $\mathbf{1 3}$ as the product in decreased yield and slightly decreased enantioselectivity. At this stage, it is difficult to understand such experimental results. However, it is speculated that the addition of the (Z)-allylcopper(I) is kinetically unfavored and the isomerization of (Z)-allylcopper (I) species to $(E)$-allylcopper(I) might occur through 1,3translocation in the present reaction conditions ${ }^{53}$. The absolute

4

NATURE COMMUNICATIONS | (2020)11:5480 | https://doi.org/10.1038/s41467-020-19293-9| www.nature.com/naturecommunications 


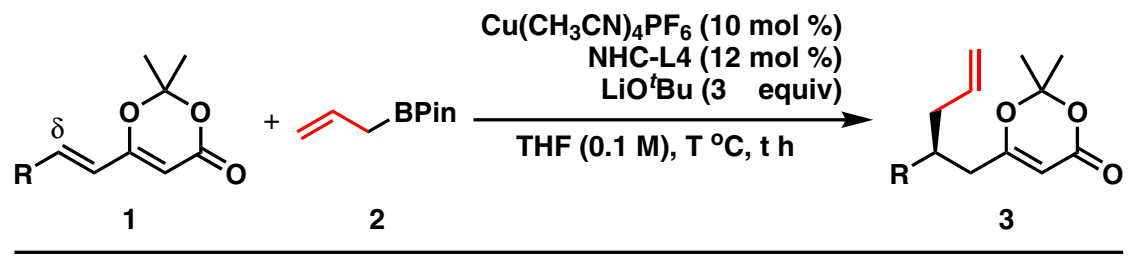

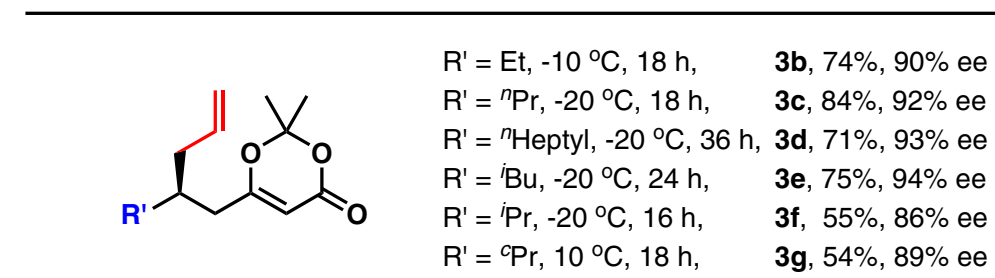<smiles>C=CC[C@H](CCc1ccccc1)CC1=CC(=O)OC(C)(C)O1</smiles>

3a, $-20{ }^{\circ} \mathrm{C}, 12 \mathrm{~h}$

$80 \%, 94 \%$ ee<smiles>C=CC[C@H](CCCCCl)CC1=CC(=O)OC(C)(C)O1</smiles>

$3 \mathbf{j},-10^{\circ} \mathrm{C}, 12 \mathrm{~h}$

$77 \%, 94 \%$ ee

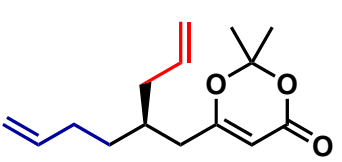

$3 \mathrm{~h}, 15^{\circ} \mathrm{C}, 12 \mathrm{~h}$

$64 \%, 89 \%$ ee

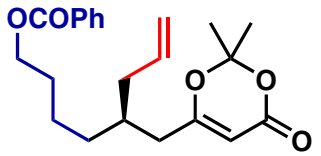

3k, $0{ }^{\circ} \mathrm{C}, 12 \mathrm{~h}$

$89 \%, 92 \%$ ee

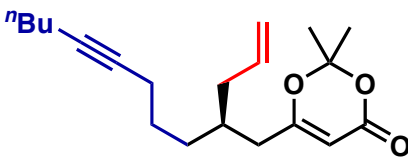

$3 \mathbf{i}, 15{ }^{\circ} \mathrm{C}, 24 \mathrm{~h}$

$69 \%, 88 \%$ ee

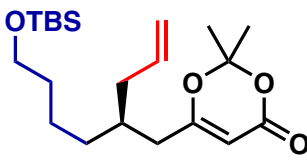

$31,10{ }^{\circ} \mathrm{C}, 21 \mathrm{~h}$

$58 \%, 91 \%$ ee

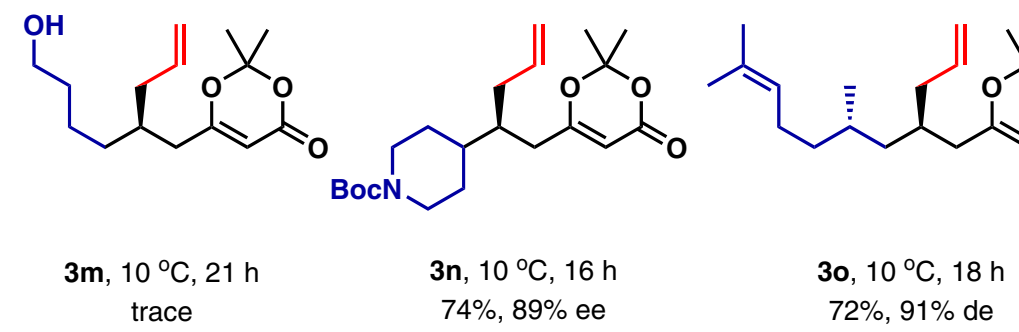

a1: $0.1 \mathrm{mmol}, 2: 0.3 \mathrm{mmol}$. Isolated yield. Enantioselectivity determined by chiral-stationaryphase HPLC analysis. Dr determined by ${ }^{1} \mathrm{H}$ NMR analysis of the crude reaction mixture.

Fig. 2 Substrate scope of (E)-2,2-dimethyl-6-alkyl-4H-1,3-dioxin-4-ones in the 1,6-conjugate allylationa. Various aliphatic substituents at $\delta$-position are studied.

configurations of 9,10 , and 11 were deduced analogically based on the stereochemical structure of $\mathbf{5 a}$. Moreover, the absolute configurations of the two stereogenic carbon centers in $\mathbf{1 3}$ were determined by its transformation (For the details, see SI). In addition, the present catalytic system was extended to the asymmetric additions with $\mathrm{PhMgBr}$ and EtMgBr. However, only racemic products were obtained ${ }^{54}$.

Demonstration of the importance of the phenol group in NHC ligands. Several ligand variants of NHC-L4 were prepared to investigate the importance of the naphthol group (Fig. 6). The allylation with NHC-L6 containing a protected naphthol group did not afford the product $\mathbf{3} \mathbf{a}$ at all. Moreover, the reaction using NHC-L7 without the naphthol moiety was fruitless. Interestingly, NHC-L8 bearing a naphthol group and a protected naphthol group was found as a good ligand as product $\mathbf{3 a}$ was generated in $32 \%$ yield with $85 \%$ ee. These control experiments demonstrate that a free naphthol moiety is indispensable for this reaction to proceed. Furthermore, the steric hindrances on the both aryls are responsible for the asymmetric induction. Our finding of the essentiality of the free phenol or naphthol in this type of NHC ligands in asymmetric catalysis with copper(I) is in accordance with Sawamura's original findings ${ }^{49-52}$.

Transformation. At last, transformations of $\mathbf{5 d}$ were performed as described in Fig. 7. An Ir-catalyzed hydroborylation of terminal olefin moiety in $\mathbf{5 d}$ afforded boronate $\mathbf{1 4}$ in $62 \%$ yield $^{55}$. The olefin-metathesis between $\mathbf{5 d}$ and 4-methylstyrene with $10 \mathrm{~mol} \%$ Hoveyda-Grubbs catalyst 2nd generation produced $(E)$-olefin 15 in $71 \%$ yield at $40{ }^{\circ} \mathrm{C}(>20 / 1(E)$ form $/(Z)$ form ratio). Removal of the propylidene group in $\mathbf{5 d}$ 

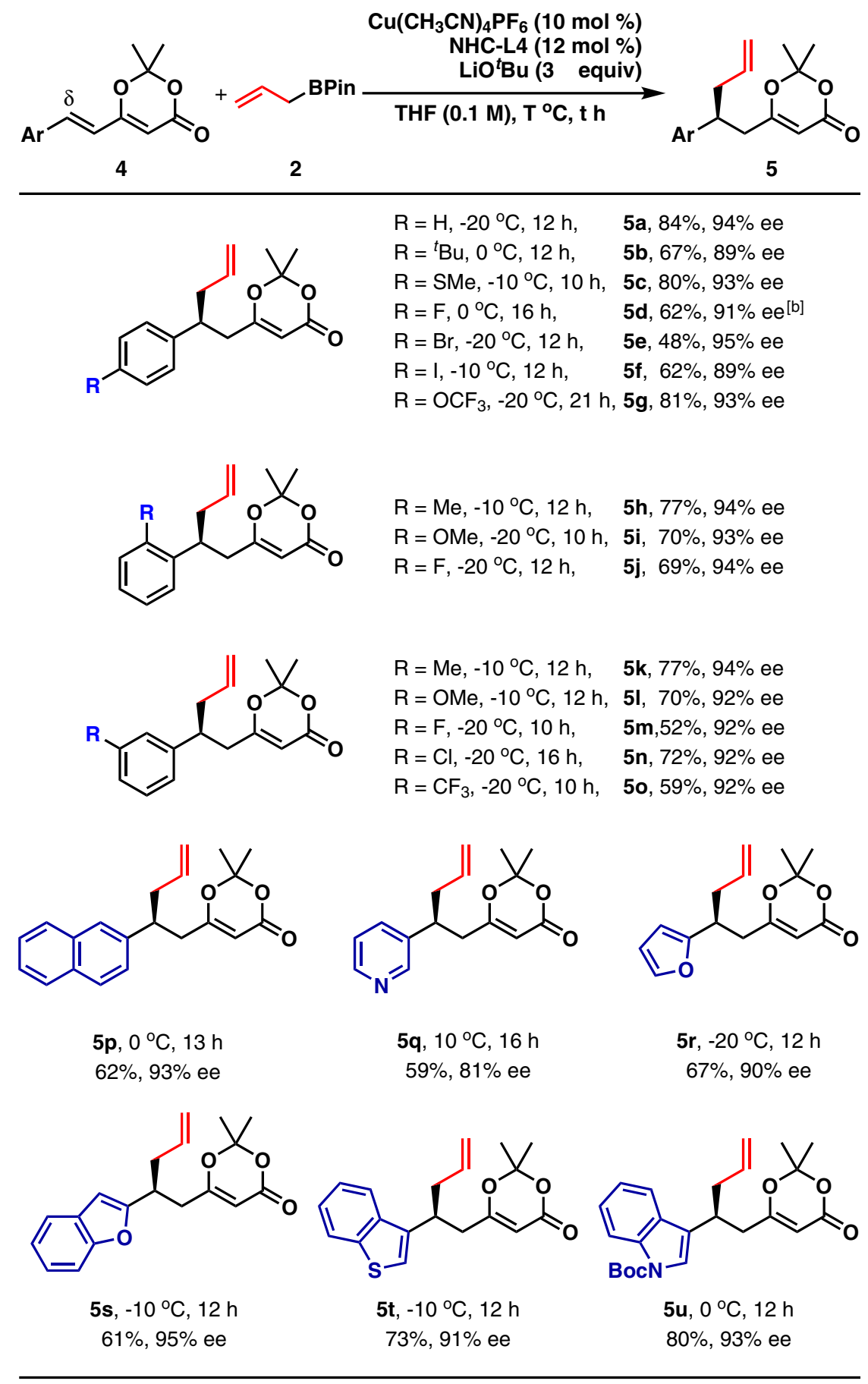

4: $0.1 \mathrm{mmol}, 2: 0.4 \mathrm{mmol}$. Isolated yield. Enantioselectivity determined by chiral-stationaryphase HPLC analysis. ${ }^{b} 1$ mmol-scale reaction.

Fig. 3 Substrate scope of (E)-2,2-dimethyl-6-aryl-4H-1,3-dioxin-4-ones in the 1,6-conjugate allylationa. Various aromatic substituents at $\delta$-position are studied.

was accomplished in $\mathrm{MeOH}$ to give $\beta$-keto-ester $\mathbf{1 6}$ in $75 \%$ yield. Then, a synthetic sequence, including the reduction of ketone unit, the formation of a mesylate, and the subsequent elimination furnished $\alpha, \beta$-unsaturated ester 17 in $60 \%$ total yield. It should be noted that $\mathbf{1 6}$ serves as a formal 1,4-conjugate allylation product of $\alpha, \beta$-unsaturated ketone and 17 serves as a formal 1,6-conjugate allylation product of $\alpha, \beta, \gamma, \delta$ unsaturated ester, which are difficult to access by known methods. Moreover, the preparation of pyrazole 18 was achieved by means of the $\beta$-keto-ester motif through a reported procedure $^{56}$.

\section{Discussion}

In summary, a catalytic asymmetric 1,6-conjugate allylation was achieved in moderate to high yields with high enantioselectivity. NHC ligands containing a phenolic hydroxyl group were found to be indispensable to enable this reaction. Both 2,2-dimethyl-6-alkenyl-4H-1,3-dioxin-4-one and allylboronate 


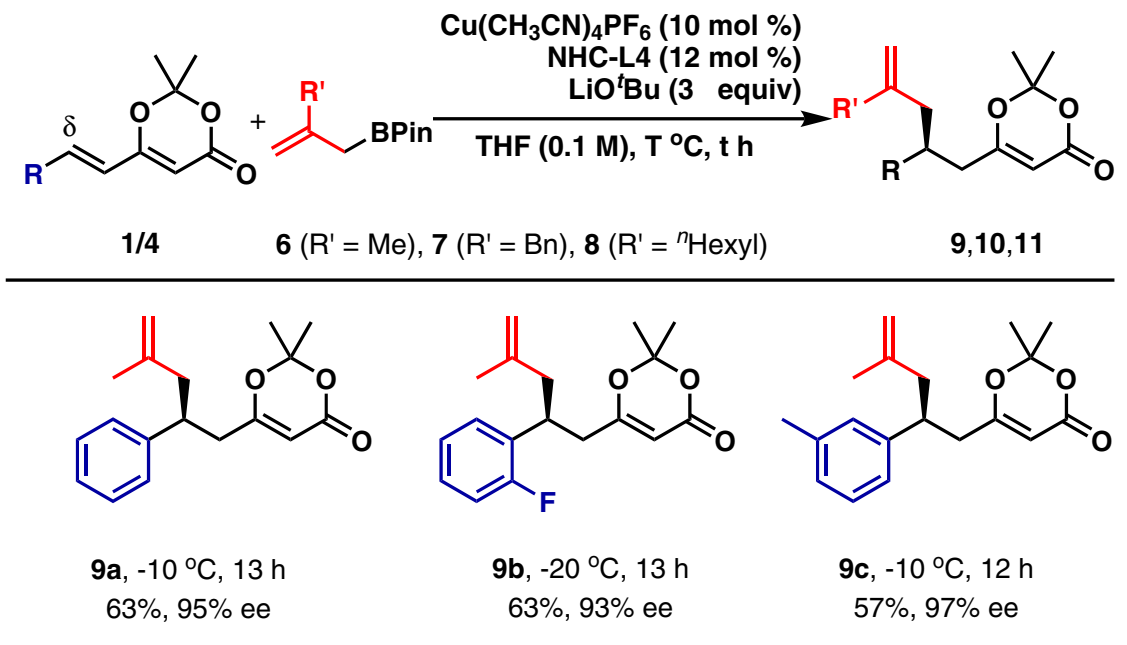

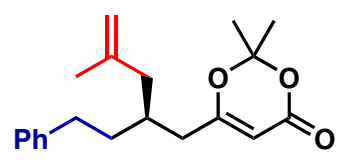

9d, $-10^{\circ} \mathrm{C}, 13 \mathrm{~h}$

$64 \%, 92 \%$ ee<smiles>C=C(CBr)C[C@H](CCc1ccccc1)CC1=CC(=O)OC(C)(C)O1</smiles>

$10,-10^{\circ} \mathrm{C}, 14 \mathrm{~h}$

$77 \%, 93 \%$ ee<smiles>C=C([GeH2])C[C@@H](CCc1ccccc1)CC1=CC(=O)OC(C)(C)O1</smiles>

$11,-10^{\circ} \mathrm{C}, 10 \mathrm{~h}$

$68 \%, 91 \%$ ee

a1/4: $0.1 \mathrm{mmol}, 6 / 7 / 8: 0.4 \mathrm{mmol}$. Isolated yield. Enantioselectivity determined by chiralstationary-phase HPLC analysis.

Fig. 4 Preliminary investigation of 1,6-conjugate allylation with 2-substituted allylboronates (6-8)a ${ }^{\text {a }}$ Both aromatic and aliphatic substituents at $\delta$-position are tried.<smiles>CC1(C)OC(=O)C=C(/C=C/c2ccccc2F)O1</smiles>

$4 \mathbf{j}$

12a, 5 equiv

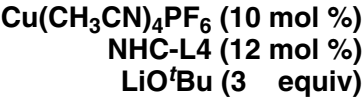

THF (0.1 M), $10^{\circ} \mathrm{C}, 12 \mathrm{~h}$

a<smiles>C=C[C@H](C)[C@H](CC1=CC(=O)OC(C)(C)O1)c1ccccc1F</smiles>

13

$59 \%, 3 / 1 \mathrm{dr}, 90 \%$ ee<smiles>CC1(C)OC(=O)C=C(/C=C/c2ccccc2F)O1</smiles>

4j

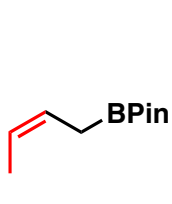

12b, 5 equiv

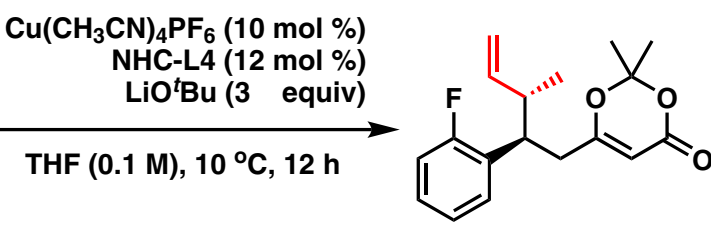

b
13

$49 \%, 3 / 1 \mathrm{dr}, 87 \%$ ee

Fig. 5 Diastereoselective 1,6-conjugate allylation. a The 1.6-conjugate allylation with (E)-allylBPin. b The 1,6-conjugate allylation with (Z)-allylBPin.

enjoyed broad substrate scopes. Several functional groups, especially alkyl halide and ester, were well tolerated in this reaction. The allyl group in the product allowed facile both hydroboration and olefin metathesis to give synthetically useful products. Moreover, the versatile dioxinone group was easily transformed to $\beta$-keto-ester moiety and $\alpha, \beta$-unsaturated ester moiety, which generated a formal 1,4-conjugate allylation product of $\alpha, \beta$-unsaturated ketone and a formal 1,6-conjugate allylation product of $\alpha, \beta, \gamma, \delta$-unsaturated ester. Detailed investigations of the mechanism are currently undertaken in our laboratory.

\section{Methods}

A general procedure for the catalytic asymmetric 1,6-conjugate allylation. A dried $25 \mathrm{ml}$ Schlenk tube equipped with a magnetic stirring bar was charged with $\mathrm{CuPF}_{6}\left(\mathrm{CH}_{3} \mathrm{CN}\right)_{4}(3.7 \mathrm{mg}, 0.01 \mathrm{mmol}, 0.1$ equiv), NHC-L4 (6.2 mg, $0.012 \mathrm{mmol}$, 0.12 equiv) and $\mathrm{LiO}^{t} \mathrm{Bu}(24.0 \mathrm{mg}, 0.3 \mathrm{mmol}, 3$ equiv) in a glove box under $\mathrm{Ar}$ atmosphere. Anhydrous THF $(1 \mathrm{ml}, 0.1 \mathrm{M})$ was added to the tube via a syringe. The resulting mixture was stirred under room temperature for $7 \mathrm{~min}$. Then 1 


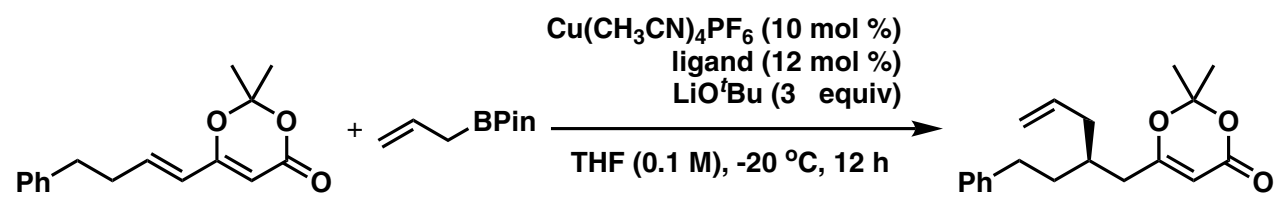

$1 a$

2

$3 a$

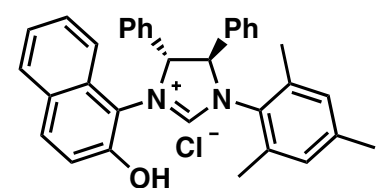

NHC-L4.HCl

3a, $86 \%, 94 \%$ ee

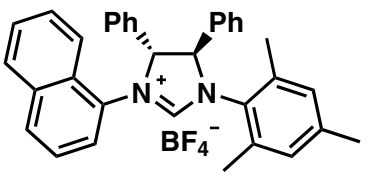

NHC-L7·HBF

3a, $0 \%$<smiles>COc1ccc2ccccc2c1N1C=[N+](c2ccccc2)[C@H](c2ccccc2)[C@H]1c1ccccc1</smiles>

NHC-L6 $\cdot \mathrm{HBF}_{4}$ 3a, $0 \%$<smiles>COc1ccc2ccccc2c1N1C=[N+](c2c(O)ccc3ccccc23)[C@H](c2ccccc2)[C@H]1c1ccccc1</smiles>

NHC-L8 $^{-H_{B F}}$

3a, $32 \%, 85 \%$ ee

Fig. 6 Control experiments with different NHC-ligands. The importance of the presence of a phenol group in NHC-ligands is demonstrated.<smiles>CC1(C)OC(=O)C=C(C[C@H](CCC[Pb])c2ccc(F)cc2)O1</smiles>

14<smiles>C=CC[C@@H](CC1=CC(=O)OC(C)(C)O1)c1ccc(F)cc1</smiles>

$5 d$
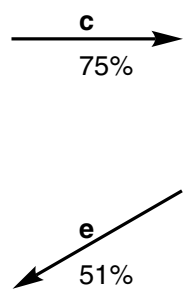

18<smiles>C=CC[C@@H](CC(=O)CC(=O)OC)c1ccc(F)cc1</smiles>

16 d $\checkmark 60 \%$<smiles>C=CC[C@H](C/C=C/C(=O)OC)c1ccc(F)cc1</smiles>

17

Fig. 7 Transformations of product 5 d. a Ir-catalyzed hydroboration. $\left[\operatorname{lr}(\mathrm{COD}) \mathrm{Cl}_{2}(5 \mathrm{~mol} \%), \mathrm{dppm}\left(\mathrm{Ph}_{2} \mathrm{PCH}_{2} \mathrm{PPh}_{2}\right)(10 \mathrm{~mol} \%), \mathrm{HBPin}(2 \mathrm{equiv}), \mathrm{CH}_{2} \mathrm{Cl}{ }_{2}\right.$ rt. b Olefin Metathesis. Hoveyda-Grubbs II catalyst (10 mol \%), 4-methylstyrene (2 equiv), $\mathrm{CH}_{2} \mathrm{Cl}_{2}, 40{ }^{\circ} \mathrm{C}$. c Transformation to $\beta$-keto-ester. MeOH, $\mathrm{K}_{2} \mathrm{CO}_{3}$, rt. d Transformation to $\alpha$, $\beta$-unsaturated ester. (1) $\mathrm{NaBH}_{4}, \mathrm{MeOH}, 0^{\circ} \mathrm{C}$; (2) $\mathrm{MsCl}, \mathrm{Et}_{3} \mathrm{~N}_{2} \mathrm{CH}_{2} \mathrm{Cl}_{2}, 0^{\circ} \mathrm{C}$ to rt. e Transformation to pyrazole. $\mathrm{NH}_{2} \mathrm{NH}_{2} \bullet \mathrm{HCl}$ (2 equiv), $\mathrm{MeOH}$, reflux.

( $0.1 \mathrm{mmol}, 1$ equiv) was added to the reaction mixture. It was cooled down to the stated temperature before adding $2(50.4 \mathrm{mg}, 0.3 \mathrm{mmol}, 3$ equiv) by a syringe. This mixture was stirred for $12-36 \mathrm{~h}$ at that temperature. Then the reaction was quenched by adding silica gel and the mixture was purified by flash silica gel column chromatography to give product 3.

\section{Data availability}

The data supporting the findings of this study are available within the article and its Supplementary Information file. Any further relevant data are available from the authors on request.
Received: 29 April 2020; Accepted: 6 October 2020;

Published online: 30 October 2020

\section{References}

1. Alexakis, A., Bäckvall, J. E., Krause, N., Pàmies, O. \& Diéguez, M. Enantioselective copper-catalyzed conjugate addition and allylic substitution reactions. Chem. Rev. 108, 2796-2823 (2008). 
2. Jerphagnon, T., Pizzuti, M. G., Minnaard, A. J. \& Feringa, B. L. Recent advances in enantioselective copper-catalyzed 1,4-addition. Chem. Soc. Rev. 38, 1039-1075 (2009).

3. Thaler, T. \& Knochel, P. Copper-catalyzed asymmetric Michael addition of magnesium, zinc, and aluminum organometallic reagents: efficient synthesis of chiral molecules. Angew. Chem. Int. Ed. 48, 645-648 (2009).

4. Tang, Q. et al. Asymmetric catalytic formal 1,4-allylation of $\beta, \gamma$-unsaturated $\alpha$ ketoesters: allylboration/oxy-Cope rearrangement. Angew. Chem. Int. Ed. 58, 11846-11851 (2019).

5. Wada, R., Oisaki, K., Kanai, M. \& Shibasaki, M. Catalytic enantioselective allylboration of ketones. J. Am. Chem. Soc. 126, 8910-8911 (2004).

6. Wada, R. et al. Catalytic enantioselective allylation of ketoimines. J. Am. Chem. Soc. 128, 7687-7691 (2006).

7. Shi, S.-L., Xu, L.-W., Oisaki, K., Kanai, M. \& Shibasaki, M. Identification of modular chiral bisphosphines effective for $\mathrm{Cu}(\mathrm{I})$-catalyzed asymmetric allylation and propargylation of ketones. J. Am. Chem. Soc. 132, 6638-6639 (2010).

8. Vieira, E. M., Snapper, M. L. \& Hoveyda, A. H. Enantioselective synthesis of homoallylic amines through reactions of (pinacolato)allylborons with aryl-, heteroaryl-, alkyl-, or alkene-substituted aldimines catalyzed by chiral C1symmetric NHC-Cu complexes. J. Am. Chem. Soc. 133, 3332-3335 (2011)

9. Wei, X.-F., Xie, X.-W., Shimizu, Y. \& Kanai, M. Copper(I)-catalyzed enantioselective addition of enynes to ketones. J. Am. Chem. Soc. 139, 4647-4650 (2017).

10. Yue, W.-J., Zhang, C.-Y. \& Yin, L. Asymmetric vinylogous aldol-type reactions of aldehydes with allyl phosphonate and sulfone. iScience 14, 88-99 (2019).

11. Kawai, J., Chikkade, P. K., Shimizu, Y. \& Kanai, M. In situ catalytic generation of allylcopper species for asymmetric allylation: toward $1 \mathrm{H}$-isochromene skeletons. Angew. Chem. Int. Ed. 52, 7177-7180 (2013).

12. Meng, F., Jang, H., Jung, B. \& Hoveyda, A. H. Cu-catalyzed chemoselective preparation of 2-(pinacolato)boron-substituted allylcopper complexes and their in situ site-, diastereo-, and enantioselective additions to aldehydes and ketones. Angew. Chem. Int. Ed. 52, 5046-5051 (2013).

13. Chikkade, P. K., Shimizu, Y. \& Kanai, M. Catalytic enantioselective synthesis of 2-(2-hydroxyethyl)indole scaffolds via consecutive intramolecular amidocupration of allenes and asymmetric addition of carbonyl compounds. Chem. Sci. 5, 1585-1590 (2014)

14. Jiang, L. et al. Highly diastereo- and enantioselective $\mathrm{Cu}$-catalyzed borylative coupling of 1,3-dienes and aldimines. Angew. Chem. Int. Ed. 55, 13854-13858 (2016).

15. Tsai, E. Y., Liu, R. Y., Yang, Y. \& Buchwald, S. L. A regio- and enantioselective $\mathrm{CuH}$-catalyzed ketone allylation with terminal allenes. J. Am. Chem. Soc. 140, 2007-2011 (2018).

16. Liu, R. Y., Zhou, Y., Yang, Y. \& Buchwald, S. L. Enantioselective allylation using allene, a petroleum cracking byproduct. J. Am. Chem. Soc. 141, 2251-2256 (2019).

17. Cui, Y., Yamashita, Y. \& Kobayashi, S. Facile preparation of allylzinc species from allylboronates and zinc amide via a boron-to-zinc exchange process and their reactions with carbonyl compounds, imines and hydrazones. Chem. Commun. 48, 10319-10321 (2012).

18. Cui, Y., Li, W., Sato, T., Yamashita, Y. \& Kobayashi, S. Catalytic use of zinc amide for transmetalation with allylboronates: general and efficient catalytic allylation of carbonyl compounds, imines, and hydrazones. Adv. Synth. Catal. 355, 1193-1205 (2013)

19. Wadamoto, M., Ozasa, N., Yanagisawa, A. \& Yamamoto, H. BINAP/AgOTf/ $\mathrm{KF} / 18$-Crown-6 as new bifunctional catalysts for asymmetric Sakurai-Hosomi allylation and Mukaiyama aldol reaction. J. Org. Chem. 68, 5593-5601 (2003).

20. Wadamoto, M. \& Yamamoto, H. Silver-catalyzed asymmetric Sakurai-Hosomi allylation of ketones. J. Am. Chem. Soc. 127, 14556-14557 (2005).

21. Naodovic, M., Wadamoto, M. \& Yamamoto, H. Enantioselective Ag-catalyzed allylation of aldimines. Eur. J. Org. Chem. 2009, 5129-5131 (2009).

22. Wadamoto, M., Naodovic, M. \& Yamamoto, H. Stereochemical studies of Agcatalyzed Hosomi-Sakurai reaction using chiral silanes. Eur. J. Org. Chem. 2009, 5132-5134 (2009)

23. Chakrabarti, A., Konishi, H., Yamaguchi, M., Schneider, U. \& Kobayashi, S. Indium(I)-catalyzed asymmetric allylation, crotylation, and $\alpha$-chloroallylation of hydrazones with rare constitutional and high configurational selectivities. Angew. Chem. Int. Ed. 49, 1838-1841 (2010).

24. Huang, Y.-Y., Chakrabarti, A., Morita, N., Schneider, U. \& Kobayashi, S. A catalytic asymmetric borono variant of Hosomi-Sakurai reactions with N,O aminals. Angew. Chem. Int. Ed. 50, 11121-11124 (2011).

25. Shizuka, M. \& Snapper, M. L. Catalytic enantioselective Hosomi-Sakurai conjugate allylation of cyclic unsaturated ketoesters. Angew. Chem. Int. Ed. 47, 5049-5051 (2008).

26. Sieber, J. D., Liu, S. \& Morken, J. P. Catalytic conjugate addition of allyl groups to styryl-activated enones. J. Am. Chem. Soc. 129, 2214-2215 (2007).
27. Sieber, J. D. \& Morken, J. P. Asymmetric Ni-catalyzed conjugate allylation of activated enones. J. Am. Chem. Soc. 130, 4978-4983 (2008).

28. Brozek, L. A., Sieber, J. D. \& Morken, J. P. Catalytic enantioselective conjugate allylation of unsaturated methylidene ketones. Org. Lett. 13, 995-997 (2011)

29. Li, X., Meng, F., Torker, S., Shi, Y. \& Hoveyda, A. H. Catalytic enantioselective conjugate additions of (pin)B-Substituted allylcopper compounds generated in situ from butadiene or isoprene. Angew. Chem. Int. Ed. 55, 9997-10002 (2016).

30. Meng, F. et al. Catalytic erantioselective 1,6-conjugate additions of propargyl and allyl groups. Nature 537, 387-393 (2016).

31. Huang, Y., Torker, S., Li, X., del Pozo, J. \& Hoveyda, A. H. Racemic vinylallenes in catalytic enantioselective multicomponent processes: rapid generation of complexity through 1,6-conjugate additions. Angew. Chem. Int. Ed. 58, 2685-2691 (2019).

32. Kuang, Y. et al. Catalytic asymmetric conjugate allylation of coumarins. Org Lett. 13, 3814-3817 (2011).

33. Yanagida, Y., Yazaki, R., Kumagai, N. \& Shibasaki, M. Asymmetric synthesis of isothiazoles through $\mathrm{Cu}$ catalysis: direct catalytic asymmetric conjugate addition of allyl cyanide to a, $\beta$-unsaturated thioamides. Angew. Chem. Int. Ed. 50, 7910-7914 (2011).

34. Silva, E. M. P. \& Silva, A. M. S. 1,6-conjugate addition of nucleophiles to $\alpha, \beta, \gamma$, $\delta$-diunsaturated systems. Synthesis 44, 3109-3128 (2012).

35. Mauduit, M., Baslé, O., Clavier, H., Crévisy, C. \& Denicourt-Nowicki, A Metal Catalyzed Asymmetric Nucleophilic Addition to Electron-Deficient Alkenes in Comprehensive Organic Synthesis II, Vol. 4 (eds Molander, G. A. \& Knochel, P.) 189 (Elsevier, Amsterdam, 2014).

36. den Hartog, T., Harutyunyan, S. R., Font, D., Minnaard, A. J. \& Feringa, B. L. Catalytic enantioselective 1,6-conjugate addition of Grignard reagents to linear dienoates. Angew. Chem. Int. Ed. 47, 398-401 (2008).

37. Hénon, H., Mauduit, M. \& Alexakis, A. Regiodivergent 1,4 versus 1,6 asymmetric copper-catalyzed conjugate addition. Angew. Chem. Int. Ed. 47, 9122-9124 (2008)

38. Wencel-Delord, J., Alexakis, A., Crévisy, C. \& Mauduit, M. Enantioselective 1,6-conjugate addition to cyclic dienones catalyzed by the Cu-DiPPAM complex. Org. Lett. 12, 4335-4337 (2010).

39. Magrez, M., Wencel-Delord, J., Alexakis, A., Crévisy, C. \& Mauduit, M. Significant asymmetric amplification in enantioselective $\mathrm{Cu} / \mathrm{DiPPAM}$ catalyzed 1,6- and 1,4-conjugate additions of diethylzinc to (di)enones. Org. Lett. 14, 3576-3579 (2012).

40. Tissot, M. \& Alexakis, A. Enantio- and regioselective conjugate addition of organometallic reagents to linear polyconjugated nitroolefins. Chem. Eur. J. 19, 11352-11363 (2013)

41. Magrez-Chiquet, M. et al. Enantioselective 1,6-conjugate addition of dialkylzinc reagents to acyclic dienones catalyzed by Cu-DiPPAM complexextension to asymmetric sequential 1,6/1,4-conjugate addition. Chem. Eur. J. 19, 13663-13667 (2013).

42. Jahier-Diallo, C. et al. Multicomponent synthesis of chiral bidentate unsymmetrical unsaturated n-heterocyclic carbenes: copper-catalyzed asymmetric C-C bond formation. Chem. Eur. J. 21, 993-997 (2015).

43. den Hartog, T. et al. On the mechanism of Cu-catalyzed enantioselective extended conjugate additions: a structure-based approach. ACS Catal. 5, 560-574 (2015).

44. Blons, C. et al. Asymmetric sequential Cu-catalyzed 1,6/1,4-conjugate additions of hard nucleophiles to cyclic dienones: determination of absolute configurations and origins of enantioselectivity. Chem. Eur. J. 23, 7515-7525 (2017).

45. Guo, Y., Kootstra, J. \& Harutyunyan, S. R. Catalytic regio- and enantioselective alkylation of conjugated dienyl amides. Angew. Chem. Int. Ed. 57, 13547-13550 (2018).

46. Halbert, S. et al. Catalytically active species in copper/DiPPAM-catalyzed 1,6 asymmetric conjugate addition of dialkylzinc to dienones: a computational overview. ChemCatChem 11, 4108-4115 (2019).

47. Clavier, H., Coutable, L., Guillemin, J.-C. \& Mauduit, M. New bidentate alkoxy-NHC ligands for enantioselective copper-catalysed conjugate addition. Tetrahedron 16, 921-924 (2005)

48. Park, J. K. et al. A chiral 6-membered N-heterocyclic carbene copper(i) complex that induces high stereoselectivity. Org. Lett. 12, 5008-5011 (2010).

49. Harada, A., Makida, Y., Sato, T., Harada, A. \& Sawamura, M. Coppercatalyzed enantioselective allylic alkylation of terminal alkyne pronucleophiles. J. Am. Chem. Soc. 136, 13932-13939 (2014).

50. Ohmiya, H., Zhang, H., Shibata, S., Harada, A. \& Sawamura, M. Construction of quaternary stereogenic carbon centers through copper-catalyzed enantioselective allylic alkylation of azoles. Angew. Chem. Int. Ed. 55, 4777-4780 (2016).

51. Yasuda, Y., Ohmiya, H. \& Sawamura, M. Copper-catalyzed enantioselective allyl-allyl coupling between allylic boronates and phosphates with a phenol/ N-heterocyclic carbene chiral ligand. Angew. Chem. Int. Ed. 55, 10816-10820 (2016). 
52. Hojoh, K., Ohmiya, H. \& Sawamura, M. Synthesis of $\alpha$-quaternary formimides and aldehydes through umpolung asymmetric copper catalysis with isocyanides. J. Am. Chem. Soc. 139, 2184-2187 (2017).

53. Lipshutz, B. H. \& Hackmann, C. Conjugate addition reactions of allylic copper species derived from Grignard reagents: synthetic and spectroscopic aspects. J. Org. Chem. 59, 7437-7444 (1994).

54. Wipf, P. \& Grenon, M. Toward the total synthesis of lophotoxin-New methodologies and synthetic strategies. Can. J. Chem. 84, 1226-1241 (2006).

55. Yamamoto, Y., Fujikawa, R., Umemoto, T. \& Miyaura, N. Iridium-catalyzed hydroboration of alkenes with pinacolborane. Tetrahedron 60, 10695-10700 (2004).

56. Guillou, S., Bonhomme, F. J. \& Janin, Y. L. An improved preparation of 3alkoxypyrazoles. Synthesis 2008, 3504-3508 (2008).

\section{Acknowledgements}

We gratefully acknowledge the financial support from the National Natural Science Foundation of China (No. 21672235, No. 21871287, and No. 21922114), the Program of Shanghai Academic/Technology Research Leader (20XD1403600), the Strategic Priority Research Program of the Chinese Academy of Sciences (No. XDB20000000), CAS Key Laboratory of Synthetic Chemistry of Natural Substances and Shanghai Institute of Organic Chemistry.

\section{Author contributions}

L.Y. and P.T. conceived and designed the study. C.Y.S. and Z.Z.P. performed the synthetic experiments and analyzed data for all new compounds. L.Y. wrote the paper.

\section{Competing interests}

The authors declare no competing interests.

\section{Additional information}

Supplementary information is available for this paper at https://doi.org/10.1038/s41467020-19293-9.

Correspondence and requests for materials should be addressed to P.T. or L.Y.

Peer review information Nature Communications thanks Senmiao Xu and the other, anonymous, reviewer(s) for their contribution to the peer review of this work.

Reprints and permission information is available at http://www.nature.com/reprints

Publisher's note Springer Nature remains neutral with regard to jurisdictional claims in published maps and institutional affiliations.

(c) (i) Open Access This article is licensed under a Creative Commons Attribution 4.0 International License, which permits use, sharing, adaptation, distribution and reproduction in any medium or format, as long as you give appropriate credit to the original author(s) and the source, provide a link to the Creative Commons license, and indicate if changes were made. The images or other third party material in this article are included in the article's Creative Commons license, unless indicated otherwise in a credit line to the material. If material is not included in the article's Creative Commons license and your intended use is not permitted by statutory regulation or exceeds the permitted use, you will need to obtain permission directly from the copyright holder. To view a copy of this license, visit http://creativecommons.org/ licenses/by/4.0\%

(C) The Author(s) 2020 